\title{
Fragmentation and swelling of various coals during devolatilization in a fluidized bed
}

\author{
Dragoljub Dakič, Geert van der Honing* and Marinus Valk* \\ Boris Kidrič Institute, PO Box 522, Belgrade, Yugos/avia \\ * Department of Thermal Engineering, University of Twente, PO Box 217, 7500 AE \\ Enschede, The Netherlands \\ (Received 25 July 1988; revised 22 November 1988)
}

\begin{abstract}
The combustion rate of large coal particles in a fluidized bed is to a large extent controlled by the external diffusion. This rate will depend on the particle diameter. There are several processes that affect this diameter: the combustion process itself; attrition; fragmentation; and swelling. The last two processes can cause large diameter changes in a relatively short period, mainly during devolatilization. The experiments reported in this paper are aimed at finding a simple relationship between some properties of the parent coal particles, and the fragmentation and swelling during devolatilization.
\end{abstract}

(Keywords: swelling; fluidized beds; devolatilization)

Coal is a heterogeneous substance, but fixed carbon, volatile matter, moisture and minerals can be easily distinguished. The relative percentage of these constituents can be of importance for some of the combustion characteristics. Most mathematical models for coal combustion in fluidized beds are based on the theory of a single burning char particle ${ }^{1-5}$. Some of these models have been verified with ideal fuel particles (i.e. graphite), but the validity for non-ideal conditions has not yet been established, which may say less about the correctness of the models than about the uncertainty in the initial conditions. For a mathematical description of the complete combustion process in a fluidized bed, including carbon efficiency and $\mathrm{NO}_{x}$-emission, it is important to know the mass of coal char per volume unit, the number of coal char particles, and their size distribution. The carbon load is directly related to the carbon particle burnout time and therefore it is important that any process that changes this burnout time is understood.

The reliability of these models will be affected if the initial conditions concerning the single char particles are incorrectly stated. To find these conditions, it is necessary to discover correlations that predict fragmentation and the developing of the char pore structure, i.e. swelling, density and porosity changes. Primary fragmentation has been mentioned by several authors, although not as the main object of their research. Experiments to determine fragmentation and swelling are usually executed with particles contained in a basket. Some researchers have taken photographs of coal particles at the bed surface to study behaviour during devolatilization ${ }^{6-11}$. Primary fragmentation shortens the devolatilization time, as smaller, fragmented particles heat up faster ${ }^{12}$.

The main reason for attrition, or secondary fragmentation, occurring during char combustion, is the increase of coal porosity. This may create mechanically weak bridges between different parts of the particle. If these bridges break, the coal particle is fragmented ${ }^{13}$. This mechanism accounts for part of the carbon loss. Many authors have already reported on the extent of secondary fragmentation and elutriation of char fines ${ }^{7,10,14-18}$, but this phenomenon is not in the scope of the present research.

\section{PHYSICAL MODEL OF COAL PARTICLES DURING DEVOLATILIZATION IN A FLUIDIZED BED}

Although some empirical correlations exist for fragmentation $^{19}$ and swelling of coal particles, there is no model to explain these phenomena. By observing the physical and chemical processes before and during devolatilization it is hoped that a descriptive model can be made.

Three phases can be distinguished in the period under consideration (Figure 1). Phase 0 illustrates the parent coal particles as they are fed into the fluidized bed. During phase 1 , the water evaporates from the coal surface and out of the pores. Devolatilization begins at the start of phase 2 . In phase 2 , different coal types may behave differently. Three particular cases can be recognised.

1. The number of particles does not change and they keep approximately the same form and size.

2. The particles fragment, but the total volume stays approximately the same.

3. Swelling occurs as well as fragmentation. The coal structure changes quite dramatically.

The amount of swelling and fragmentation occurring during devolatilization is thought to be affected by: the amount of volatile matter evolved; the average weight of the hydrocarbons formed during devolatilization; particle diameter; bed temperature; and the amount of open pores in the coal structure.

The volatile matter content of coal can vary from 2 to $\approx 45 \mathrm{wt} \%$, depending on coal rank. However, the real devolatilization conditions can have a considerable effect on the actual yield. These volatiles will be evolved within a few seconds for small particles, and up to a minute for larger particles. In particular, volatiles formed inside the 


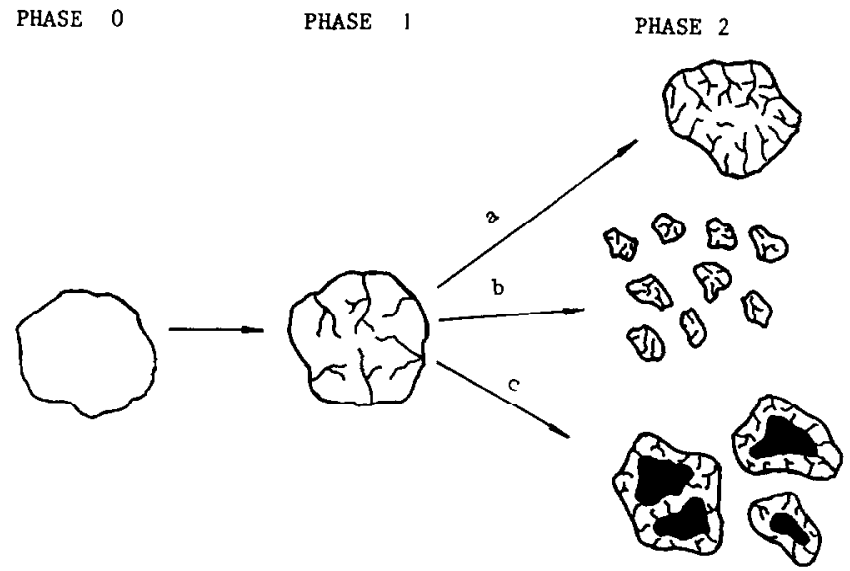

Figure 1 Schematic representation of the behaviour of large coal particles before and during devolatilization

particle will encounter resistance by the limiting transport capacity of the developing pore structure. The result is a pressure build up inside the particle. When this pressure gets too high, either the particle breaks under the strain, or plastic deformation occurs to accommodate more gases. The first phenomenon is fragmentation, the second swelling.

The major products of devolatilization are hydrogen, methane, ethane, higher hydrocarbons, carbon monoxide, carbon dioxide and chemically bound water. The proportionate amounts of these gascous products vary during the devolatilization. The chemically bound water and carbon oxides are released during the first part of the devolatilization process, while the hydrogen and hydrocarbons evolve later ${ }^{5}$. The molecular weight of the hydrocarbons determines the rheological behaviour of the volatiles. Light hydrocarbons behave like gases, while heavier ones may show a liquid or even plastic behaviour. Heavier hydrocarbons will make the coal particle less brittle, and the internal pressure is likely to be released by swelling.

As particle diameter is the maximum distance evolved volatiles have to travel through the particle, the resistance experienced by escaping volatiles is proportional to this distance, i.e. the internal pressure for small particles will be less than for larger particles. The bed temperature can affect total volatile yield and volatile composition. The rate of heating is largely determined by the particle sizes of both the bed and the coal particles. The porosity of the parent coal particle determines to a large extent the transport capacity available to the volatiles before the more porous char structure is formed. This char structure is the result of the space previously occupied by the volatiles and the deformation caused by the pressure build up.

Apart from these individual effects, there are also interactions to be considered. Experiments by Howard et al. $^{20}$ indicate that under certain conditions volatiles participate in secondary reactions. Two causes that enhance the effect of these reactions are increased pressure and prolonged residence time of the volatiles in the particle. Generally, the secondary reactions reduce the total volatile yield. It is thought that cracking and polymerization form chemical compounds that condensate in the particle. The molecular weight of the hydrocarbons formed by polymerization is higher than that of the original volatiles, and therefore they enhance swelling.
Both the internal pressure and the residence time are determined by the amount of volatiles to be evolved, the pore structure of the parent coal particle and the diameter of the particle.

For large coal particles used for fluidized bed combustion, it is thought that the following parameters have a significant effect on primary fragmentation and swelling: particle diameter; volatile matter content; and parent coal structure characterized by its porosity.

To quantify the first two parameters is straightforward, but it is difficult to determine the porosity in a simple manner. However it is possible that there is a relationship between the water content of air dried (ad) coal according ISO nr 1988-1975(E), the so-called 'equilibrium moisture', and the porosity of the parent coal particle. Mercury porosimetry, Table 1, indicates that this equilibrium moisture content is a reasonable measure of the porosity.

Two final parameters should be considered: particle diameter, which is a geometric parameter, and the pore resistance number (PRN), which is is linked to coal type and is defined as

$$
\text { PRN }=\frac{\text { volatile matter content }}{\text { equilibrium moisture content }}
$$

\section{EXPERIMENTAL}

Coal particles varying in size from 2.0 to $15 \mathrm{~mm}$ were used. The coals were of a wide range of rank. The main purpose was to establish the size of the char particles at the beginning of char combustion. For that reason, the experiments were concerned in particular with the phenomena occurring during devolatilization. Experiments were carried out with small batches of coal particles, so that errors made because of the heterogeneous nature of coal were largely eliminated. The results presented in this paper are average values found for each different diameter fraction of the coal particles.

\section{Experimental apparatus and technique}

The experimental apparatus is shown in Figure 2. The reactor was made from a quartz glass tube, $100 \mathrm{~mm}$ i.d. and $80 \mathrm{~cm}$ high. Fluidization gas was fed in at the bottom through a sintered quartz plate, acting as a porous distributor. The reactor and a preheater coil for the fluidization gas were placed in an electric thermostat controlled oven. The fluidization gas consisted of nitrogen and/or oxygen, mixed in any desired proportion. Sand was used as the bed material. A parallel line was constructed to cool down the reactor and its fluidizing contents in an inert nitrogen atmosphere. Spherical precision ground connectors made it possible to take a reactor from the hot oven and place it on the parallel cooling line. During cooling, the bed was fluidized with

Table 1 Porosity from mercury porosimetry

\begin{tabular}{lll}
\hline & $\begin{array}{l}\text { Mercury } \\
\text { porosimetry } \\
\text { posority } \\
(\text { vol\%) }\end{array}$ & $\begin{array}{l}\text { Equilibrium } \\
\text { moisture } \\
\text { content } \\
(\mathrm{wt} \%)\end{array}$ \\
\hline Polish 8 & 3.46 & 2.15 \\
NCB low volatile marine & 1.7 & 0.8 \\
Scott's & 2.47 & 2.18 \\
South African anthracite & 2.84 & 2.02
\end{tabular}


a velocity slightly higher than the minimum fluidization velocity. The bed temperature and the flue gas composition were continuously monitored through the experiments.

\section{Experimental conditions}

The experimental conditions are listed in Table 2, and the proximate and ultimate analyses and the crucible swelling number (CSN) (ISOnr 501-1974(E)) of the coal types used are given in Table 3. Depending on coal type and diameter fraction, $1-5 \mathrm{~g}$ batches were fed on top of the bed. The mass of the batch was chosen so that the oxygen concentration did not drop below 5 vol\% during combustion of the volatiles.

\section{Determination of typical times}

The first part of the investigation was the determination of the devolatilization and burnout times for the different coal types and diameter fractions. The batches were allowed to burn out completely in the bed. During the experiments a rise in bed temperature of $5-10^{\circ} \mathrm{C}$ could not be avoided, but the bed temperature was allowed to return to the set value before the next experiment was started.

To estimate the devolatilization times, both the detection of hydrocarbons and the visibility of a flame

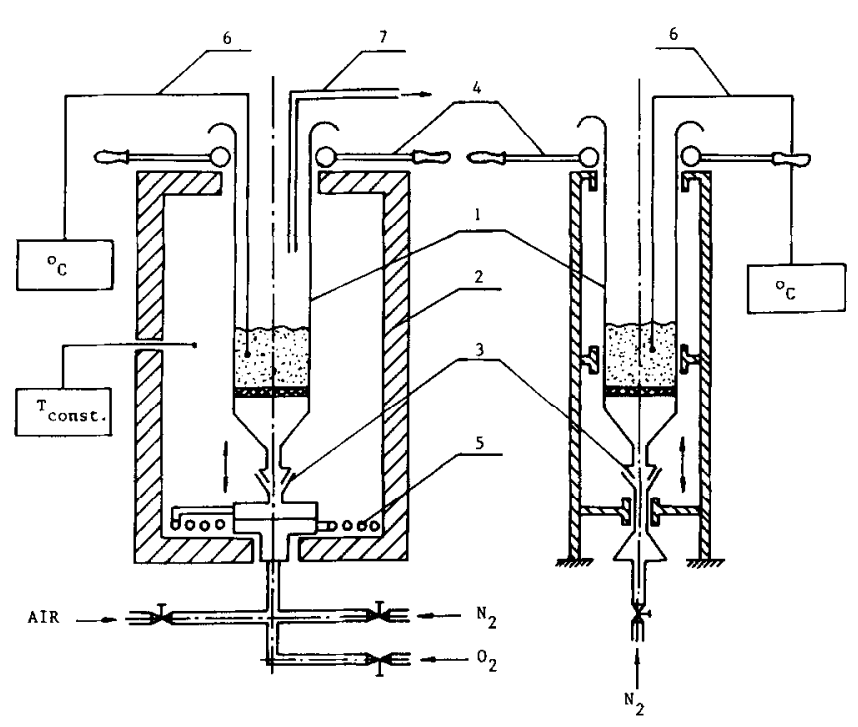

Figure 2 Experimental apparatus: 1, quartz reactor; 2, electric oven; 3 , spherical connectors; 4 , handle bars; 5 , air preheater coil; 6 , thermocouple; 7 , gas sampling probe were used. For the smaller size fractions, the response time of the $\mathrm{HC}$-meter was too long, so only the flame-out time was used. For the other fractions, the times when these phenomena ceased to occur were averaged to find the devolatilization time. The char burn-out time was determined by the $\mathrm{CO}_{2}$ concentration of the flue gases. The times established at a bed temperature of $850^{\circ} \mathrm{C}$ are shown in Table 4.

\section{Fragmentation and swelling}

One of the main problems in studying fragmentation and swelling in a fluidized bed is the separation of the char particles from the bed particles. To achieve this, the complete reactor with its contents was cooled down. If this cooling is done while the bed is just fluidizing, the mechanical damage will be minimal, the cooling will be fast enough, and to a certain extent segregation between bed and char particles will occur, so that the char particles can be collected from the top of the bed. Visual observations confirm that additional fragmentation and attrition can be neglected during the cooling period. Mechanical damage during the separation of char and bed particles should be minimized by very careful handling. In these experiments, it was impossible to separate particles of diameter $<1 \mathrm{~mm}$ if they had submerged in the bed during cooling.

Photographs were taken to quantify the effect of primary fragmentation and swelling during devolatilization. The batch consisting of $\approx 11-170$ coal particles and the char particles recovered from the cooled reactor were both photographed so that all particles could be clearly distinguished. A typical set of photographs can be seen in Figure 3. The photographs were analysed by a digital image analyser. Data were gathered on the average area (volume), perimeter (surface), diameter of the particles and on the number of particles. The results of each 'before-after' experiment were correlated. It is

Table 2 Experimental conditions

\begin{tabular}{ll}
\hline Bed temperature & $850^{\circ} \mathrm{C}$ \\
Particle diameter & $0.55 \mathrm{~mm}$ \\
Fluidization velocity & $0.264 \mathrm{~m} \mathrm{~s}^{-1}$ \\
Unexpanded bed height & $0.1 \mathrm{~m}$ \\
Coal fractions & $2-2.8 \mathrm{~mm}$ \\
& $4-4.75 \mathrm{~mm}$ \\
& $6.3-8 \mathrm{~mm}$ \\
& $8-10 \mathrm{~mm}$ \\
Fluidization gas: $\mathrm{N}_{2} / \mathrm{O}_{2}$ volume ratio & $10-15 \mathrm{~mm}$ \\
& $85 / 15$
\end{tabular}

Table 3 Chemical analyses of coal

\begin{tabular}{|c|c|c|c|c|c|c|c|c|c|c|c|}
\hline & \multicolumn{5}{|c|}{ Ultimate analysis } & \multicolumn{4}{|c|}{ Proximate analysis } & \multirow[b]{3}{*}{$\mathrm{CSN}$} & \multirow[b]{3}{*}{ PRN } \\
\hline & \multirow[b]{2}{*}{ C } & \multicolumn{3}{|c|}{ (wt\% dry basis) } & \multirow[b]{2}{*}{$\mathbf{O}$} & \multicolumn{4}{|c|}{ (wt \% equilibrium moisture basis) } & & \\
\hline & & $\mathbf{H}$ & $\mathbf{N}$ & $s$ & & $\begin{array}{l}\text { Fixed } \\
\text { carbon }\end{array}$ & $\begin{array}{l}\text { Volatile } \\
\text { matter }\end{array}$ & Ash & $\begin{array}{l}\text { Equilibrium } \\
\text { moisture }\end{array}$ & & \\
\hline Polish 8 & 74.3 & 4.70 & 1.26 & 0.78 & 7.27 & 55.69 & 30.72 & 11.45 & 2.15 & 1 & 14.29 \\
\hline NCB low volatile marine & 81.84 & 4.54 & 1.39 & 0.95 & 3.20 & 67.50 & 23.65 & 8.05 & 0.80 & $4.5-5$ & 29.56 \\
\hline Scott's & 71.51 & 4.35 & 1.39 & 0.65 & 8.98 & 47.40 & 37.66 & 12.72 & 2.18 & $3-3.5$ & 17.26 \\
\hline Kolubara Yugoslavian lignite & 52.76 & 4.92 & 1.44 & 1.44 & 20.45 & 37.91 & 34.33 & 16.93 & 10.83 & 0 & 3.17 \\
\hline Australian high sulphur content & 66.67 & 5.06 & 1.22 & 4.96 & 5.64 & 45.25 & 36.67 & 16.00 & 1.98 & 2.5 & 18.52 \\
\hline Rheinbraun German brown coal & 64.22 & 4.92 & 0.60 & 0.48 & 24.34 & 38.54 & 45.12 & 4.67 & 11.66 & 0 & 3.87 \\
\hline
\end{tabular}


Table 4 Devolatilization and burn out times

\begin{tabular}{|c|c|c|c|c|c|c|}
\hline \multirow[b]{2}{*}{ Coal type } & $2.0-2.8$ & n) & \multicolumn{2}{|c|}{$\begin{array}{l}\text { Coal fraction } \\
4.0-4.75(\mathrm{~mm})\end{array}$} & \multicolumn{2}{|c|}{$6.3-8.0(\mathrm{~mm})$} \\
\hline & $\begin{array}{l}\text { Devolatilization } \\
\text { time } \\
\text { (s) }\end{array}$ & $\begin{array}{l}\text { Burn out } \\
\text { time } \\
\text { (min) }\end{array}$ & $\begin{array}{l}\text { Devolatilization } \\
\text { time } \\
\text { (s) }\end{array}$ & $\begin{array}{l}\text { Burn out } \\
\text { time } \\
(\min )\end{array}$ & $\begin{array}{l}\text { Devolatilization } \\
\text { time } \\
\text { (s) }\end{array}$ & $\begin{array}{l}\text { Burn out } \\
\text { time } \\
\text { (min) }\end{array}$ \\
\hline Polish 8 & 7.6 & 5.25 & 15.7 & 9.75 & 27.0 & 15.0 \\
\hline NCB low volatile marine & 6.8 & 6.6 & 16.6 & 12.7 & 25.1 & 18.7 \\
\hline Scott's & 8.2 & 4.55 & 16.0 & 11.2 & 29.4 & 18.6 \\
\hline Kolubara Yugoslavian lignite & $-\cdots$ & -- & 11.4 & 4.8 & 24.5 & 11.0 \\
\hline Australian high sulphur content & 8.2 & 5.1 & 16.8 & 10.5 & 30.0 & 18.5 \\
\hline Rheinbraun brown coa] & 6.2 & 3.4 & 13.5 & 6.3 & 25.5 & 12.5 \\
\hline
\end{tabular}
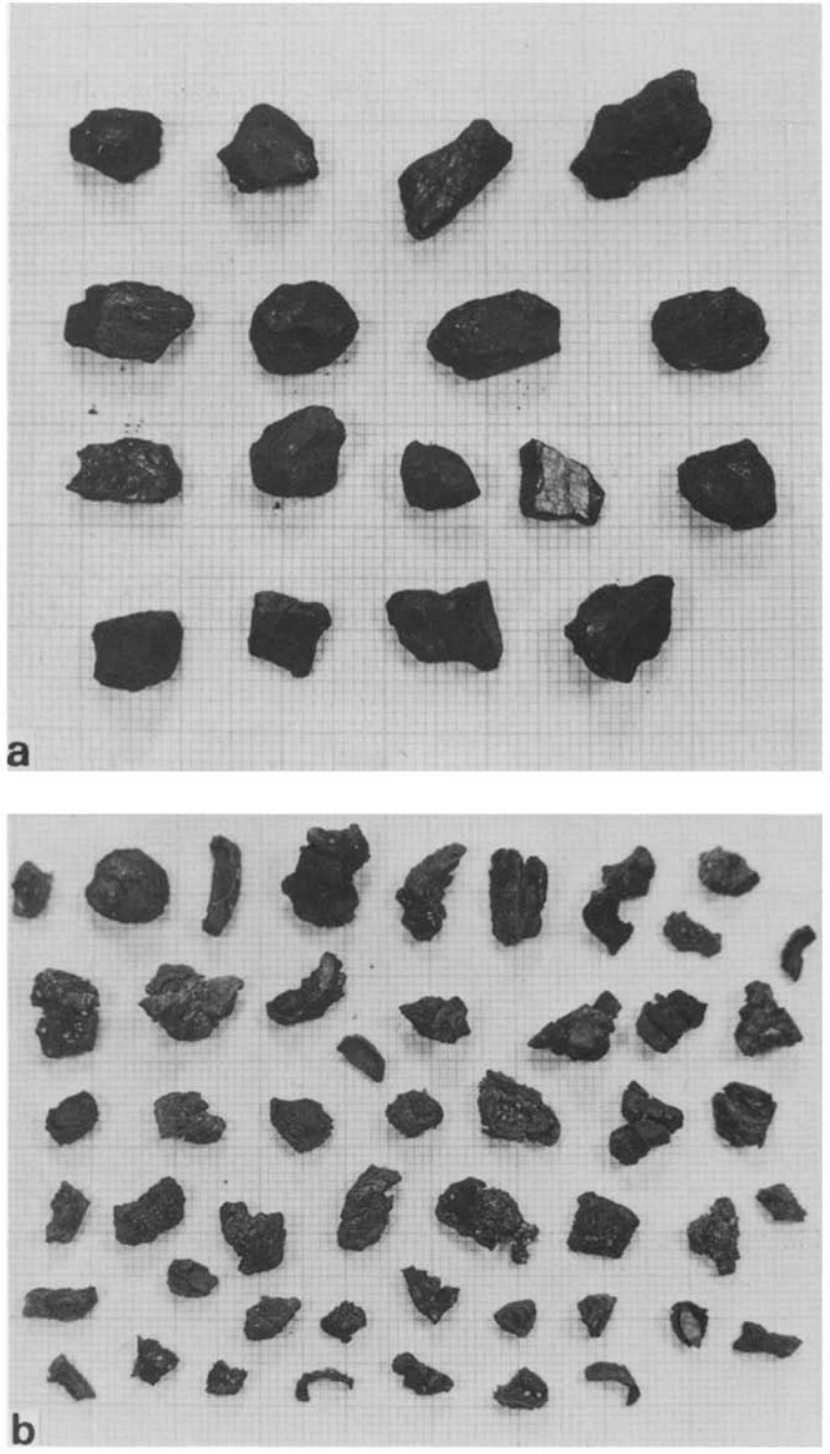

Figure 3 One batch of coal particles (Polish 8, 6.3-8 mm); a, before; b, after devolatilization at $1123 \mathrm{~K}$

possible that the natural urge of the particles to find the position with the lowest centre of gravity affects the results of this image analysis. Although this will cause similar errors for all the pictures taken, this effect was studied to exclude any possible error. Two photographs were taken of some batches: one from above and one from the side. By doing this, all three main dimensions

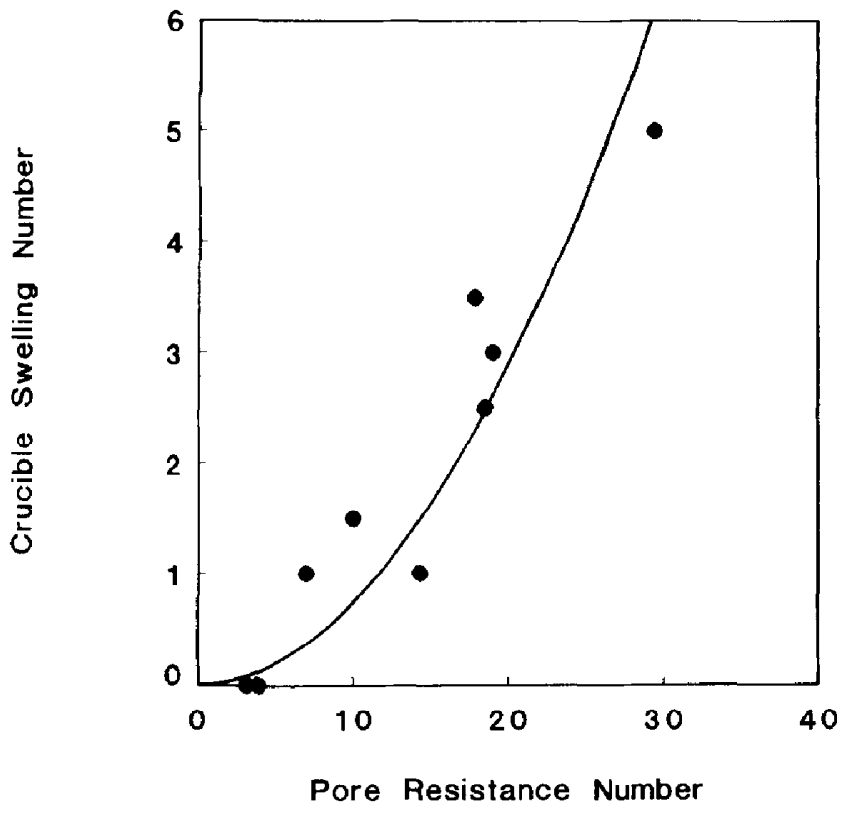

Figure 4 Crucible swelling number as a function of pore resistance number. Two points are calculated from data presented in Ref. 12

were known. It appeared that the third dimension changed proportionate to the others. The effect on the observed relative changes during devolatilization can be neglected. As the sphericity of most particles does not change to any extent during devolatilization, this is not surprising.

The relationship between crucible swelling number and pore resistance number can be seen in Figure 4, which also includes some other published results ${ }^{12}$. The correlation between CSN and PRN is found to be

$$
\mathrm{CSN}=10^{-2} \mathrm{PRN}^{1.9}
$$

A possible explanation is that a high PRN indicates an increased resistance for the volatiles to escape, resulting in a long residence time of the volatiles in the particle and a high pressure build-up, both favouring secondary polymerization reactions and swelling. If this relationship is generally valid, PRN has a few advantages over CSN. First, no complicated extra experiments have to be done to detemine PRN; and second, CSN is basically a discrete quantity. For large groups of lower rank coals this is especially inconvenient as they all have a CSN of either $0,0.5$ or 1 . PRN facilitates the categorization of these coals more precisely. 


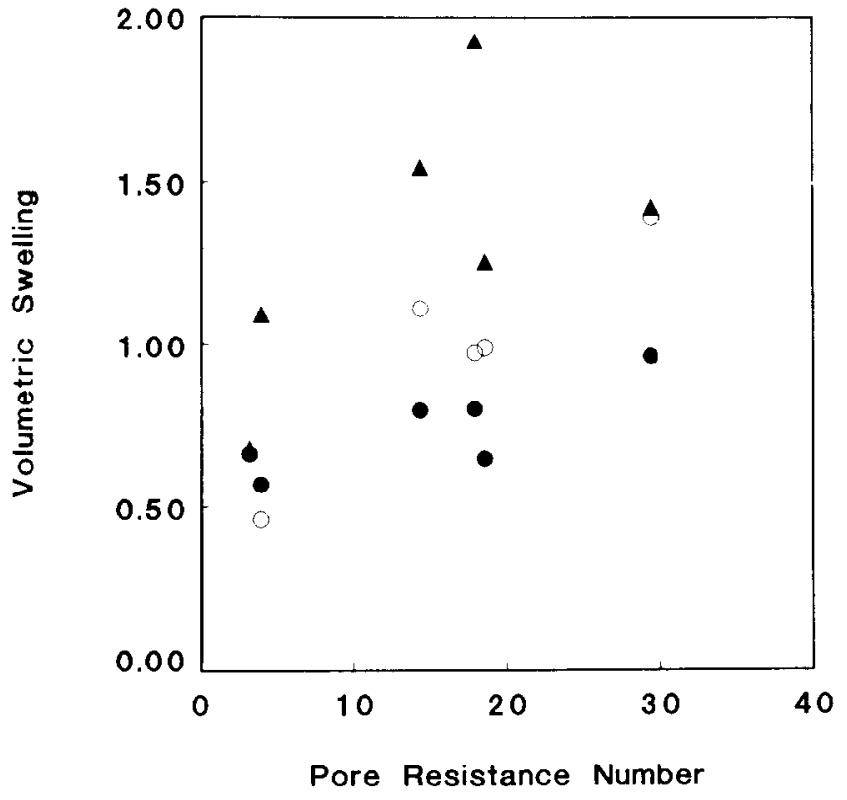

Figure 5 Volumetric swelling during devolatilization in a fluidized bed at $1123 \mathrm{~K}$. Char particle diameters: $\mathrm{O}, 2-2.8 \mathrm{~mm} ; \mathbf{0}, 4-4.75 \mathrm{~mm}$; and $\boldsymbol{A}, 6.3-8 \mathrm{~mm}$

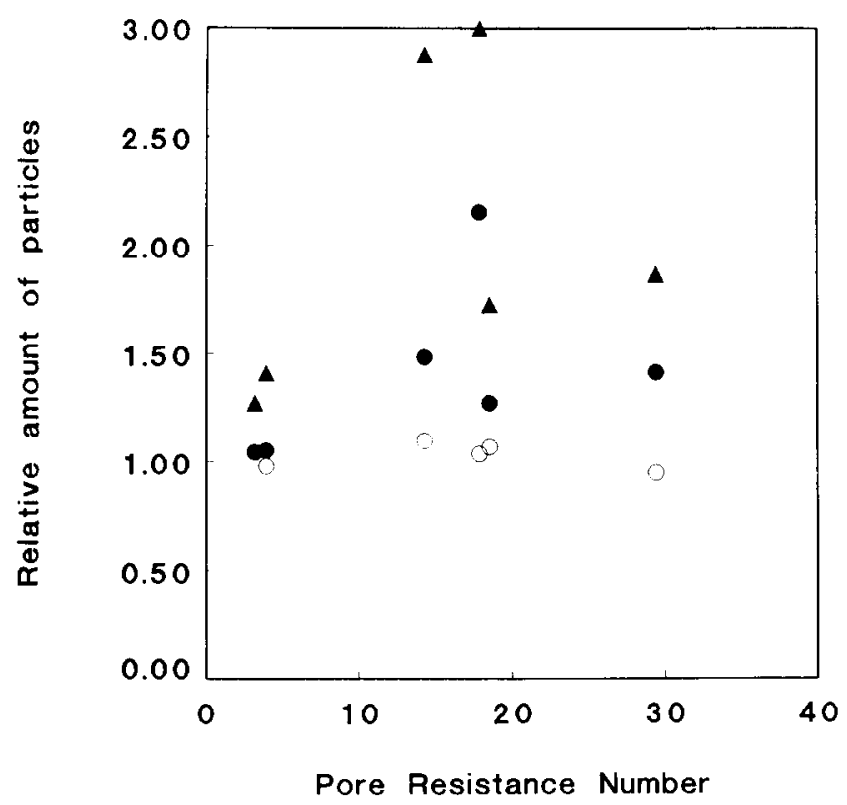

Figure 6 Relative amount of particles before and after devolatilization at $1123 \mathrm{~K}$. Char particle diameters: $0,2-2.8 \mathrm{~mm} ; 0,4.75 \mathrm{~mm}$; and $\Delta, 6.3-8 \mathrm{~mm}$

The significance of CSN for fluidized bed combustion is not clear. To be able to use the results from the image analysis to assess the effect of swelling, the total volume of the particles must be calculated. The image analyser calculates for every particle the diameter $\left(D_{\text {circle }}\right)$ of a hypothetical, round particle with the same observed cross-sectional area as the original particle

$$
D_{\text {circle }}=2 \sqrt{\frac{\text { Area }}{\pi}}
$$

If it assumed that $D_{\text {circle }}$ is also valid for the three dimensional particle, it is possible to calculate its volume. When the total amount of particles and the average $D_{\text {circle }}$ before and after every experiment are known, it is possible to calculate the relative amount of swelling that occurs:

$$
\begin{array}{r}
\text { Volumetric swelling }=\frac{\text { total volume after }}{\text { total volume before }} \\
=\mathrm{n}^{\prime \prime} \times\left(D_{\text {circle }}\right)^{3} \\
\mathrm{n}^{\prime} \times\left(D_{\text {circle }}\right)^{3}
\end{array}
$$

where $\mathrm{n}^{\prime}=$ no. of particles before devolatilization and $\mathrm{n}^{\prime \prime}=$ no. of particles after devolatilization.. It can be seen from Figure 5 that swelling also occurs in a fluidized bed, although to a lesser extent than the CSN indicates. For PRN $>12$, swelling can be noticed. A PRN of 12 indicates a CSN of 1 (Figure 4).

The best indication for fragmentation is the ratio of the amount of particles after and before the experiments. The results for the different coal types and particle fractions can be seen in Figure 6. If the fragmentation is plotted against the PRN an increased fragmentation for $P R N \approx 15$ can be seen. This can be explained as follows. For lower PRN, the pressure build-up resulting from the volatile evolution is lower because there are more pores available. Because of this lower internal pressure, there is no reason for the particles to fragment. For higher PRN the pressure build-up increases but because of the increased swelling and plastic behaviour the particles do not break easily, but instead deform.

The combined effect of fragmentation and swelling can be quantified by the ratio of the particle diameter before and after the experiment as shown in Figure 7. The plotted diameter is the diameter of a circle with the same area as the observed cross section of the particle. The last result obtained from the experiments is the "critical diameter' $\left(D_{\text {crit }}\right)$. This is defined as the diameter of the largest particle for which there is no noticeable fragmentation. Because the experiments are performed with sieve fractions, it is only possible to give an approximate value of the critical diameter. Figure 8 shows critical diameter plotted against PRN. For low PRN there is a large critical diameter. This decreases to

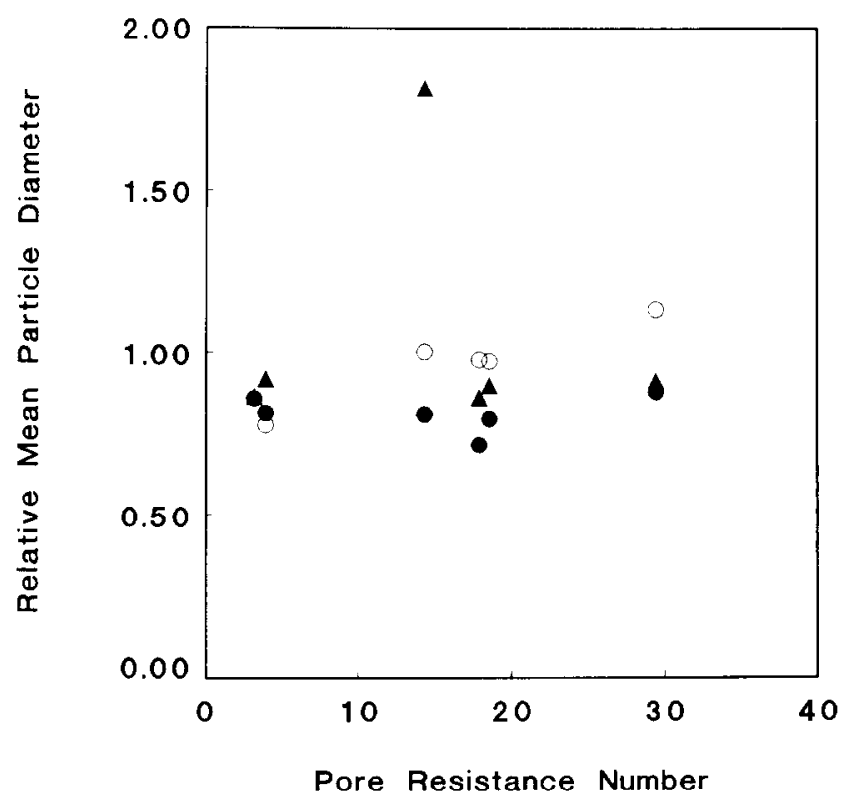

Figure 7 Relative mean particle diameter (based on the visible cross section) before and after devolatilization at $1123 \mathrm{~K}$. Char particle diameters: $0.2-2.8 \mathrm{~mm}$; 0. 4-4.75 mm; and A. $6.3-8 \mathrm{~mm}$ 


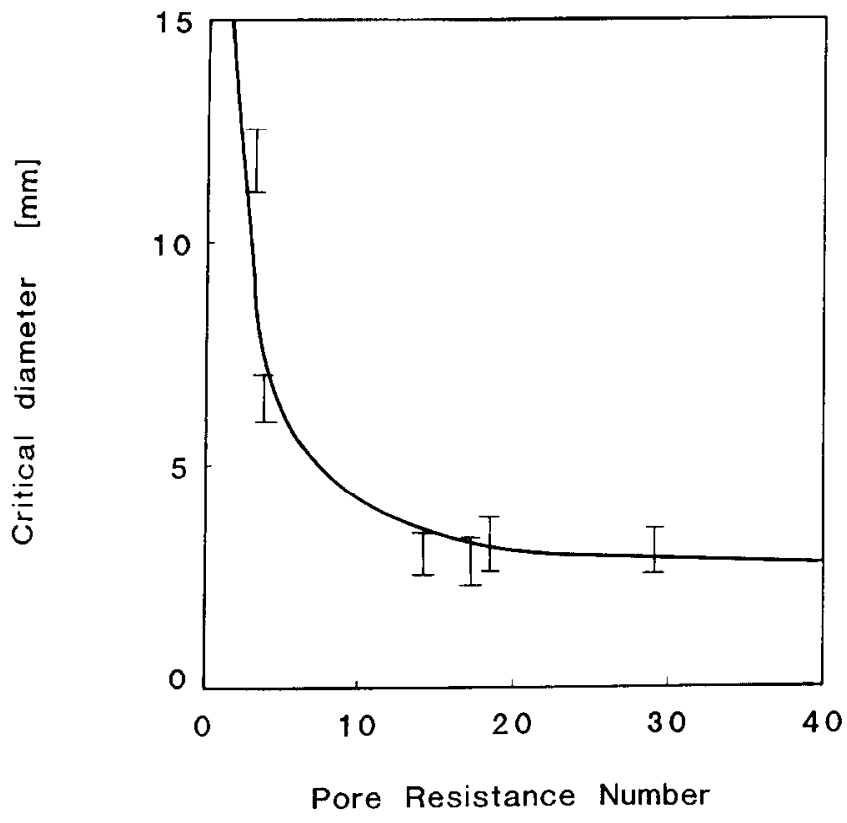

Figure 8 Relationship between pore resistance number and critical diameter (diameter at which fragmentation starts to occur)

$\mathrm{PRN}=15$ and remains almost constant for higher PRN values.

\section{CONCLUSIONS}

Six different coal types were used in this study and some conclusions can be drawn about their behaviour during devolatilization. It is hard to estimate the primary fragmentation and the CSN from the proximate or chemical analyses of the coal. The relationship found between swelling, primary fragmentation and the PRN facilitates this task. This is especially useful for the large group of lower rank coals with a CSN between 0 and 1 . The relationship found is not merely empirical. The interpretation of pore resistance number makes it possible to understand the physical processes causing fragmentation and swelling. From the theory it is clear that the ratio of the geometrical quantities before and after devolatilization must be a function of PRN, bed temperature and particle diameter, i.e.

volumetric swelling $\approx f(\mathrm{PRN}$, Tbed, $D \mathrm{p})$

$D_{\text {circle }} " / D_{\text {circle }}{ }^{\prime} \approx \mathrm{g}(\mathrm{PRN}$, Tbed, $D \mathrm{p})$

A change in behaviour was found for $P R N \approx 15$. This supports the physical interpretation given to the phenomena. Phases 1 and 2 of the model postulated previously are explained satisfactorily.

Apart from a more thorough validation of the stated relationship, some efforts could be made towards the definition and development of a random model describing primary fragmentation and swelling. The results of this study indicate that this should be possible with a two parameter model, one parameter representing a typical length scale $\left(D_{\text {crit }}\right)$ and one representing the swelling, which is a function of the bed temperature.

\section{ACKNOWLEDGEMENTS}

This work was supported by the Dutch Research Fellowship Program and was carried out during the one year research fellowship of D. Dakič at the University of Twente in Enschede, The Netherlands.

\section{REFERENCES}

1 Geoffrey, D., Sergeant, D. G. and Smith, J. W. Fuel 1973, 52, 58

2 Chakraborty, R. K. and Howard, J. R. J. Inst. Energy 1981, 55, 56

3 Bukur, B. D. and Amundson, H. R. Chem. Eng. Sci. 1981, 36, 1239

4 Prins, W. PhD Thesis Twente University, Enschede, The Netherlands, 1987

5 Borghi, G., Sarofim, A. F. and Beér, J. M. Combust. Flame 1985, 61, 1

6 Sundback, C. A., Beer, J. M. and Sarofim, A. F 20th International Symposium on Combustion, Combustion Institute, Pittsburgh, 1984, pp. 1945-1503

7 Arena, U., D'Amore, M. and Massimilla, L. AIChE J 1983, 20, 40

8 Chirone, R., Cammarota, A., D'Amore, M. and Massimilla, L. 7th International Conference on Fluidized Bed Combustion, Philadelphia, 1982, pp. 1023-1029

9 Pecanha, P. and Gibbs, B. M. 'Fluidised Combustion: is it achieving its promise?' I ondon, IJK, 1984

10 Chirone, R., D'Amore, M., Massimilla, L. and Mizza, A. AIChE. J. $1985,31,812$

11 Andrei, M. A., Sarofim, A. F.. and Beér, J. M. Combust, Flame $1985,61,17$

12 Stubington, J. F., Linjewile, M. T. and Sergeant, G. D. International Conference on Coal Science, Amsterdam, 1987, pp. 833-837

13 Kerstein, A. R. and Edwards, B. F. International Conference on Coal Science, Amsterdam, 1987, pp. 785-788

14 Donsi, D., Massimilla, L. and Miccio, M. Combust. Flame 1981, 41,57

15 Chirone, R., D'Amore, M. and Massimilla, L. 20th International Symposium on Combustion, Combustion Institute, Pittsburgh, 1984, pp. $1505-1511$

16 Salatino, P., Massimilla, L. Chem. Eng. Sci. 1985, 40, 1905

17 Walsh, P. M., Dutta, A., Cox, R. J. et al. 9th International Conference on Fluidized Bed Combustion, Boston, 1987

18 Beér, J. M., Massimilla, L. and Sarofim, A. F. 'Fluidised Combustion; systems and applications', London, UK, 1980

19 Preto, F. PhD Thesis Queen's University Kingston, Ontario, Canada, 1986, pp. 111-114

20 Anthony, D. B., Howard, J. B., Hottel, H. C. and Meissner, H. P. 15th International Symposium on Combustion, Combustion Institute, Pittsburgh, 1978, pp. 1303-1316 